Journal of Advanced Research in Fluid Mechanics and Thermal Sciences

Journal homepage: www.akademiabaru.com/arfmts.html ISSN: $2289-7879$

\title{
The Green Logistics Idea using Vacuum Insulation Panels (VIPs)
}

\author{
Assadawut Issaro ${ }^{1}$, Piyanut Saengsikhiao ${ }^{1}$, Juntakan Taweekun ${ }^{2,}{ }^{*}$, Wiriya Thongruang ${ }^{2}$ \\ Energy Technology Program, Faculty of Engineering, Prince of Songkla University, Hat Yai, Songkhla 90112, Thailand \\ Department of Mechanical Engineering, Faculty of Engineering, Prince of Songkla University, Hat Yai, Songkhla 90112, Thailand
}

\section{$\begin{array}{ll}\text { ARTICLE INFO ABSTRACT } & \text { ABT }\end{array}$}

Article history:

Received 13 November 2020

Received in revised form 27 March 2021

Accepted 28 March 2021

Available online 4 May 2021

\section{Keywords:}

Green logistics; Environmentally friendly; VIPs; Vacuum Insulation Panels

\begin{abstract}
This research aims to reduce fuel consumption in transportation systems using vacuum insulation panels (VIPs) for cold storage trucks. The material was vacuum Insulation Panels (VIPs) is a custom-made insulator using glass fibers pressed at 10 tons per square meter and the thermal conductivity conditions of the selected materials ranged between 0.0028 and $0.007 \mathrm{~W} / \mathrm{mK}$ and has a size of $12 \mathrm{~mm}$ comparative experiment method of cold storage trucks equipped with VIPs and without VIPs of 4 model frozen cars. Which has Model 1 (4 Wheels Truck), Model 2 (4 Wheels large Truck), Model 3 (6 Wheels Truck), and Model 4 (10 Wheels Truck). The sensor installation in the cold room is distributed in every wall to achieve differentiation and distribution of cold temperatures. The results are calculated as the energy saving result, it was found Model 1 (4 Wheels Truck) have best fuel savings. This research can apply other types of cold storage trucks or research in the same way as the air wall by inserting VIPs insulation inside the external insulation to reduce heat transfer.
\end{abstract}

\section{Introduction}

Logistics costs are still a business concern and national development. Especially the cost of inland transportation, which includes refrigerated and frozen vehicles. The cold supply chain management, cold supply chain management Maintaining product quality from upstream and midstream to downstream is a challenge in achieving optimal quality control and cost effectiveness [1]. Therefore, most of the costs come from the use of engine power by oil for produce cooling to maintain the product temperature. From Figure 1 overview of heat loads of cold storage, $51 \%$ heat load form through walls, $23 \%$ heat load form heaters and fans, $12 \%$ heat load form gasket area, $6 \%$ heat load form gasket area from food and $2 \%$ heat load form door openings [2]. This means that reducing the heat load that passes through the walls of the cold room is the best reduction in energy consumption [3].

\footnotetext{
* Corresponding author.

E-mail address: jantakan.t@psu.ac.th

https://doi.org/10.37934/arfmts.82.2.7286
} 


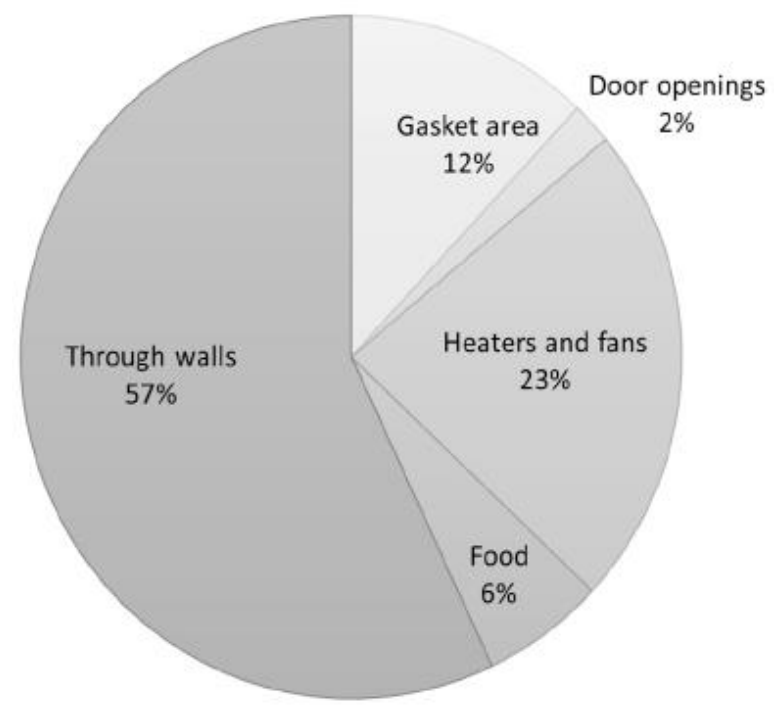

Fig. 1. Overview of heat loads of cold storage [1]

Cold storage insulators have been continuously developed from the past to the present. The progressing of cold room insulators, as shown in Figure 2 [4]. Found that, the best heat transfer coefficient (U value) value is vacuum insulated panels (VIPs) [5] and smallest size [6]. Therefore, VIPs is appropriate to be used in this research to reduce the heat load, reduce energy consumption and maintain the quality of the product [7].

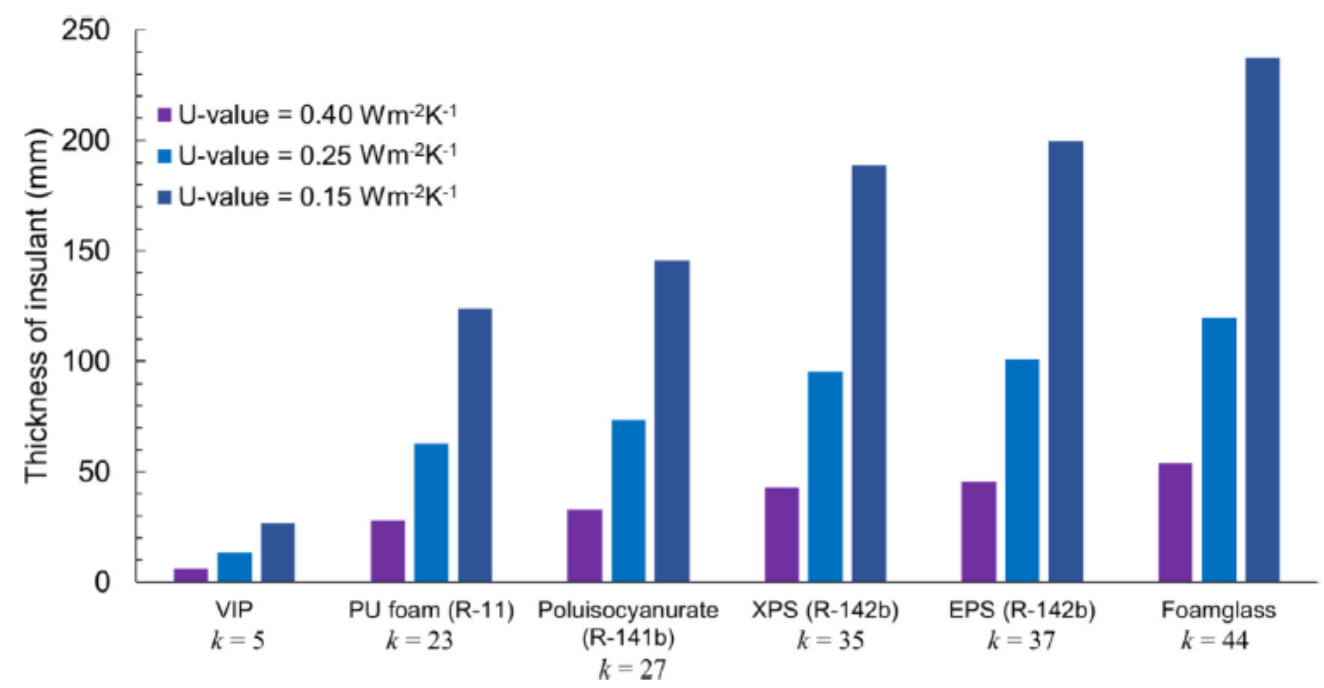

Fig. 2. The progressing of cold room insulators [4]

The logistics model uses a frozen truck with the temperature at -25 to -23 degrees Celsius, chiller trucks 0 to -2 degrees from the factory to the distribution center, and end-user. The type and size of rucks in this model will differ from length to the destination or product type. When using many types or many trucks, the cost will be high and difficult to control. The green logistics model happens to solve the effect of environmental from logistics, such as fuel in logistics and carbon dioxide from engines. This research will present the idea of the green logistics using vacuum insulation panels (VIPs) that u-value better than polyurethane foam [8]. 


\section{Materials and Methods}

The material, VIPs is a custom-made insulator using glass fibers pressed at 10 tons per square meter, then vacuumed and foil wrapped. The limitations of VIPs are currently not available in a wide variety of applications [9], as they must be prevented from impacting or kinking resulting in loss of insulation due to vacuum loss [10]. The vacuum insulated panels (VIPs), as shown in Figure 3 [11]. The thermal conductivity conditions of the selected materials ranged between 0.0028 and 0.007 $\mathrm{W} / \mathrm{m} \mathrm{K}$ and has a size of $12 \mathrm{~mm}[12]$.

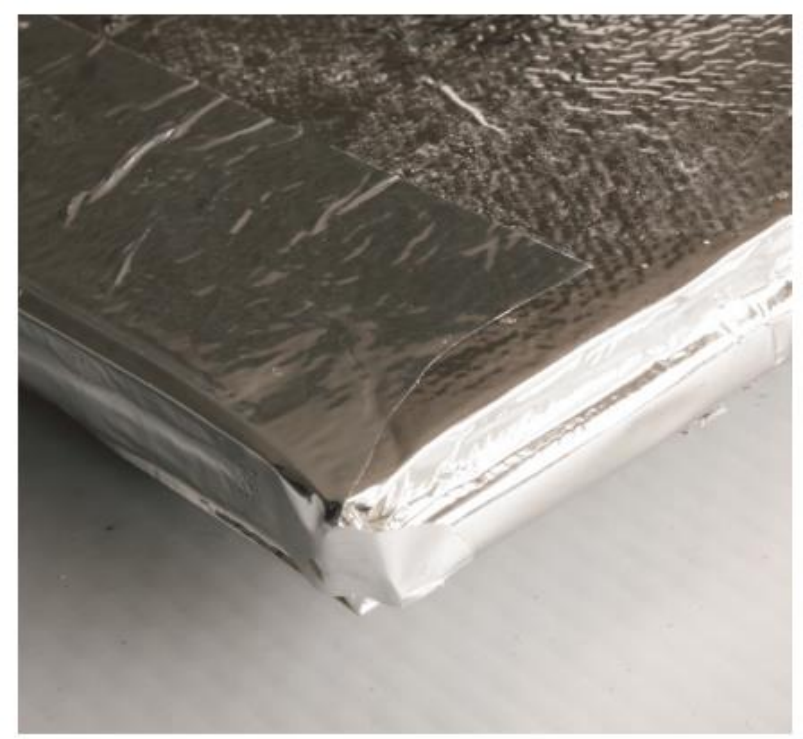

Fig. 3. The vacuum insulated panels (VIPs) [11]

The methods, Comparative experiment method of cold storage trucks equipped with VIPs and without VIPs [13] of 4 model frozen cars, as shown in Figure 4. Which has Model 1 (4 Wheels Truck), Model 2 (4 Wheels large Truck), Model 3 (6 Wheels Truck) and Model 4 (10 Wheels Truck). All 4 models of the frozen cars will have the machine specification as shown in Table 1 [14]. There are 7 temperature measurement points, consisting of 6 temperature points inside the cold room and 1 outside temperature in model 1,4. There are 6 temperature measurement points, consisting of 5 temperature points inside the cold room and 1 outside temperature in model 3 . There are 5 temperature measurement points, consisting of 4 temperature points inside the cold room and 1 outside temperature in model 2 . The sensor installation in the cold room is distributed in every wall to achieve differentiation and distribution of cold temperatures. The installation of the sensor outside the cold storage is installed behind the cold storage trucks to prevent wind and pressure coming into contact with the sensor, resulting in inaccurate measurements. The Temperature measurement location, as shown in Figure 5 [15] and how to install an additional VIPs in a cold room, as shown in Figure 6 [16]. 


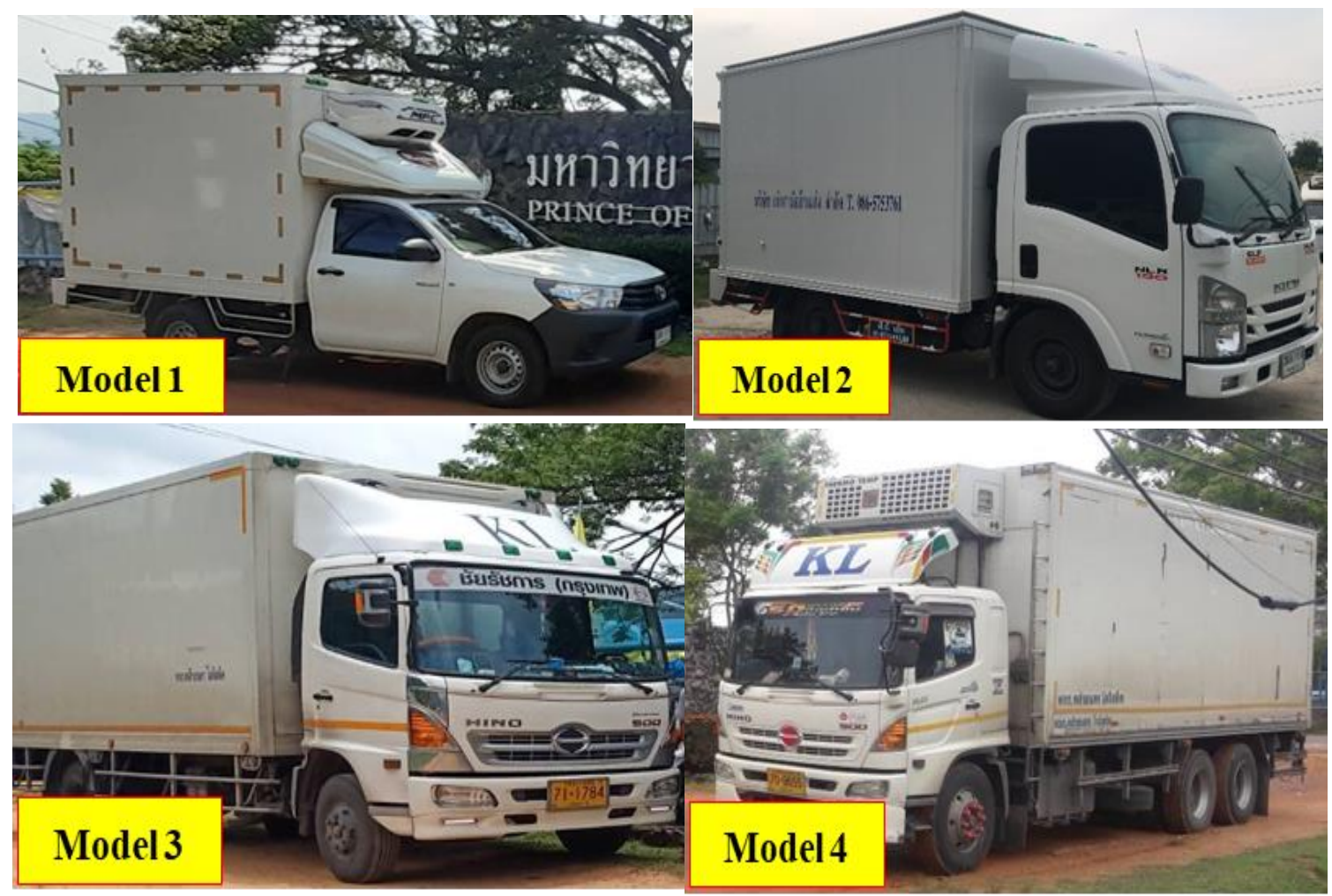

Fig. 4. Frozen cars 4 models

Table 1

Spec cars 4 model

\begin{tabular}{|c|c|c|c|c|}
\hline Item / Model & Model 1 & Model 2 & Model 3 & Model 4 \\
\hline \multicolumn{5}{|l|}{ 1. Compressor } \\
\hline 1.1 Model & SD5H14 & SD-709/TM-16 & DKS-32 & DKS-32 \\
\hline $1.2 \mathrm{CC}$ & 138 & 163 & 313 & 313 \\
\hline 2. Motor 380V & - & - & - & $7.5 \mathrm{hp}$ \\
\hline 3. Refrigerant Types & R 404A & R 404A & R 404A & R 404A \\
\hline \multicolumn{5}{|l|}{ 4. Application Range } \\
\hline 4.1 Truck Type (Wheels) & 4 & 4 & 6 & 10 \\
\hline \multicolumn{5}{|l|}{ 4.2 Cabinet Dimension ( $\mathrm{m}$ ) } \\
\hline$-W$ & 1.66 & 1.72 & 2.16 & 2.30 \\
\hline$-L$ & 2.41 & 3.38 & 6.50 & 7.10 \\
\hline$-\mathrm{H}$ & 1.60 & 1.60 & 2.15 & 2.30 \\
\hline 4.3 Room Temp. (c) & 0 or $-25 \mathrm{C}$ & 0 or $-25 \mathrm{C}$ & 0 or $-25 \mathrm{C}$ & 0 or $-25 C$ \\
\hline \multicolumn{5}{|l|}{ 5. Truck detail (Isuzu Truck) } \\
\hline$-\mathrm{CC}$ & $1900 \mathrm{CC}$ & $3000 \mathrm{CC}$ & $5200 \mathrm{CC}$ & 7790 CC \\
\hline$-h p$ & $150 \mathrm{hp}$ & $130 \mathrm{hp}$ & $150 \mathrm{hp}$ & $300 \mathrm{hp}$ \\
\hline 6. Fuel & Diesel & Diesel & Diesel & Diesel \\
\hline
\end{tabular}



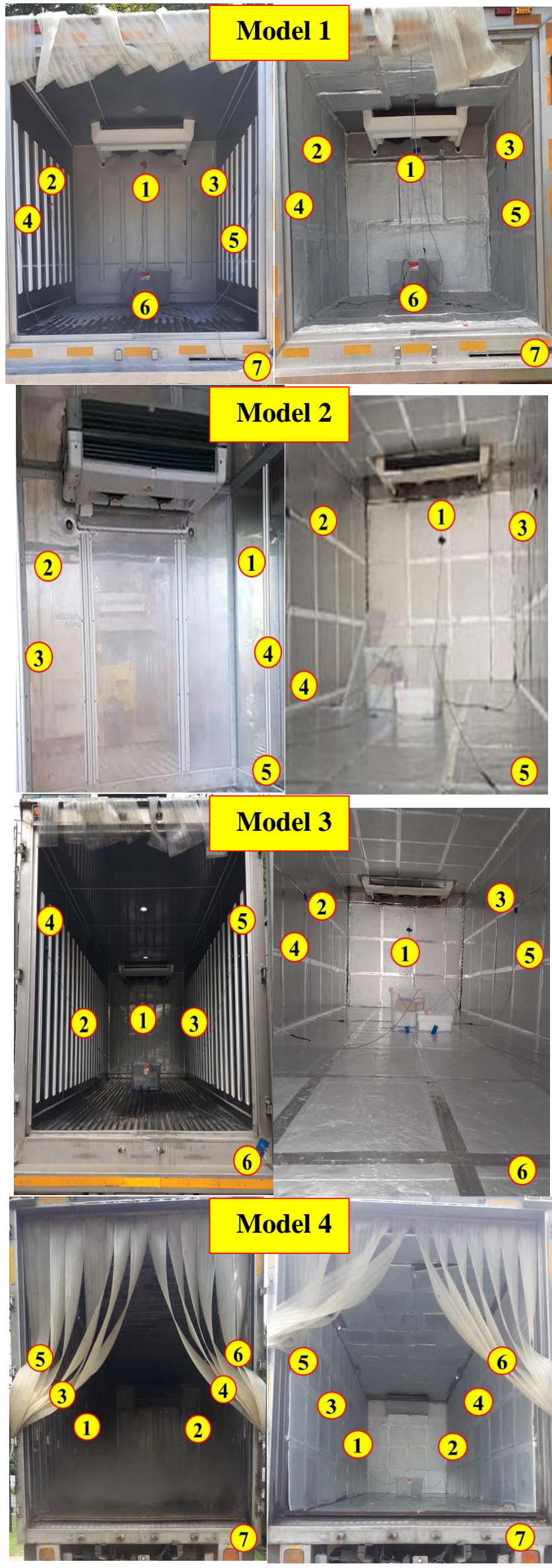

Fig. 5. The Temperature measurement location 


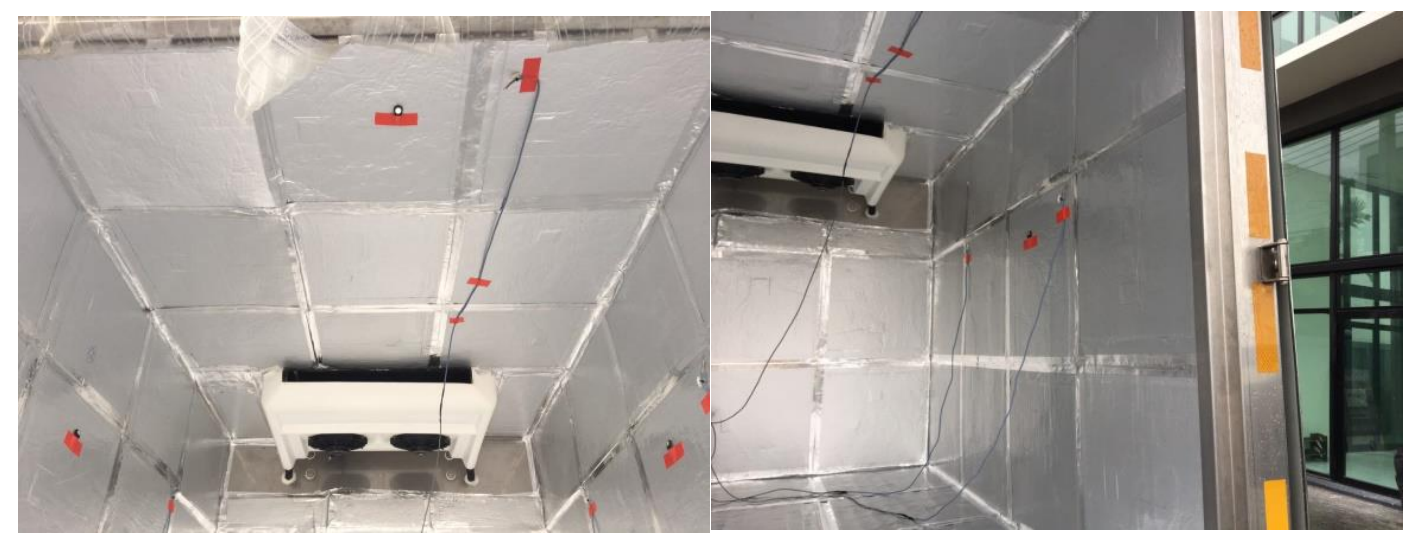

Fig. 6. How to install an additional VIP in a cold room [16]

\section{Results and Discussion}

\subsection{Model 1 - 4 Wheels Truck}

As a result of the temperature results prior to installation of VIPS, as shown in Figure 7, it was found that the refrigerated cars were controlled an average of -12 degrees and defrosted 6 times a day due to the compressor operating at -25 degrees for evaporator temperature in low temperature condition. During the defrosting time, the temperature of the freezer room will rise to a maximum of -8 degrees due to the defrosting with heater. The average temperature along the route was 944 kilometers, averaging 26 degrees. The compressor takes 5 minutes to reach the set temperature, and it rises when the compressor stops running to the point where it starts up again in 5 minutes. The compressor cut in - cut off time before install VIPs, as shown in Figure 8.

As a result of the temperature results rear to installation of VIPs, as shown in Figure 9, it was found that the refrigerated cars were controlled an average of -12 degrees and defrosted 6 times a day due to the compressor operating at -25 degrees for evaporator temperature in low temperature condition. During the defrosting time, the temperature of the freezer room will rise to a maximum of -8 degrees due to the defrosting with heater. The average temperature along the route was 944 kilometers, averaging 26 degrees. The compressor takes 10 minutes to reach the set temperature, and it rises when the compressor stops running to the point where it starts up again in 10 minutes. The compressor cut in - cut off time after install VIPs, as shown in Figure 10.

Test results show that VIPs insulation can maintain the same temperature as without VIPs insulation but the time required for cut in cut off is better to install VIPs insulation. The energy saving effect comes from the moment when the compressor is stopped, which means saving fuel to be used in cooling as a result of VIPs insulation. When all the results are calculated as the energy saving result, it is obtained that over a distance of $944 \mathrm{~km}$, the fuel price is $26.39 \mathrm{baht} /$ liter. It was found that the fuel consumption rate before VIPs installation was $7.12 \mathrm{~km} /$ liter, and compared with the after VIPs installation at $8.33 \mathrm{~km} /$ liter, the fuel savings was $17.06 \%$. 


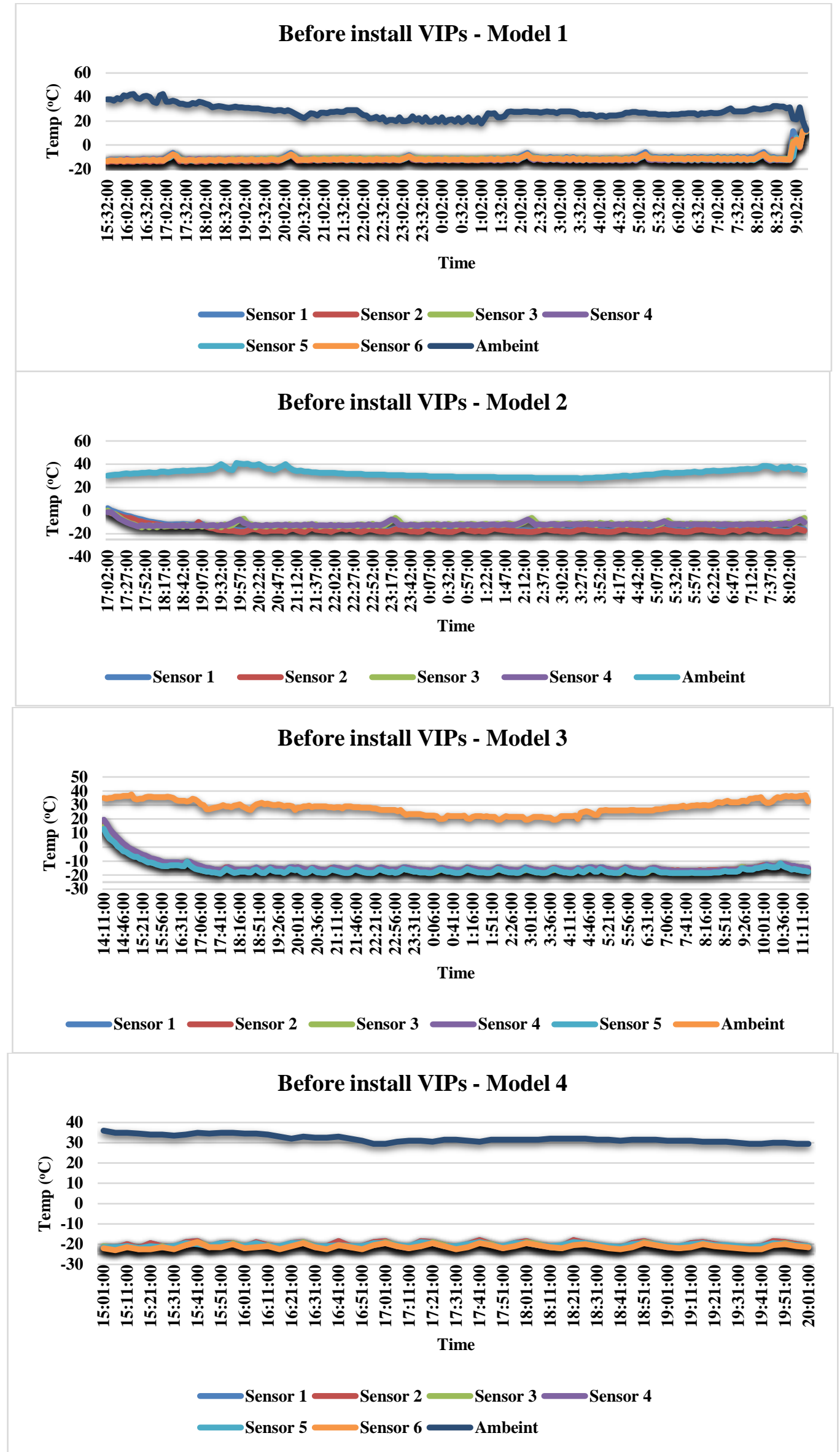

Fig. 7. Temperature results before install VIPS 


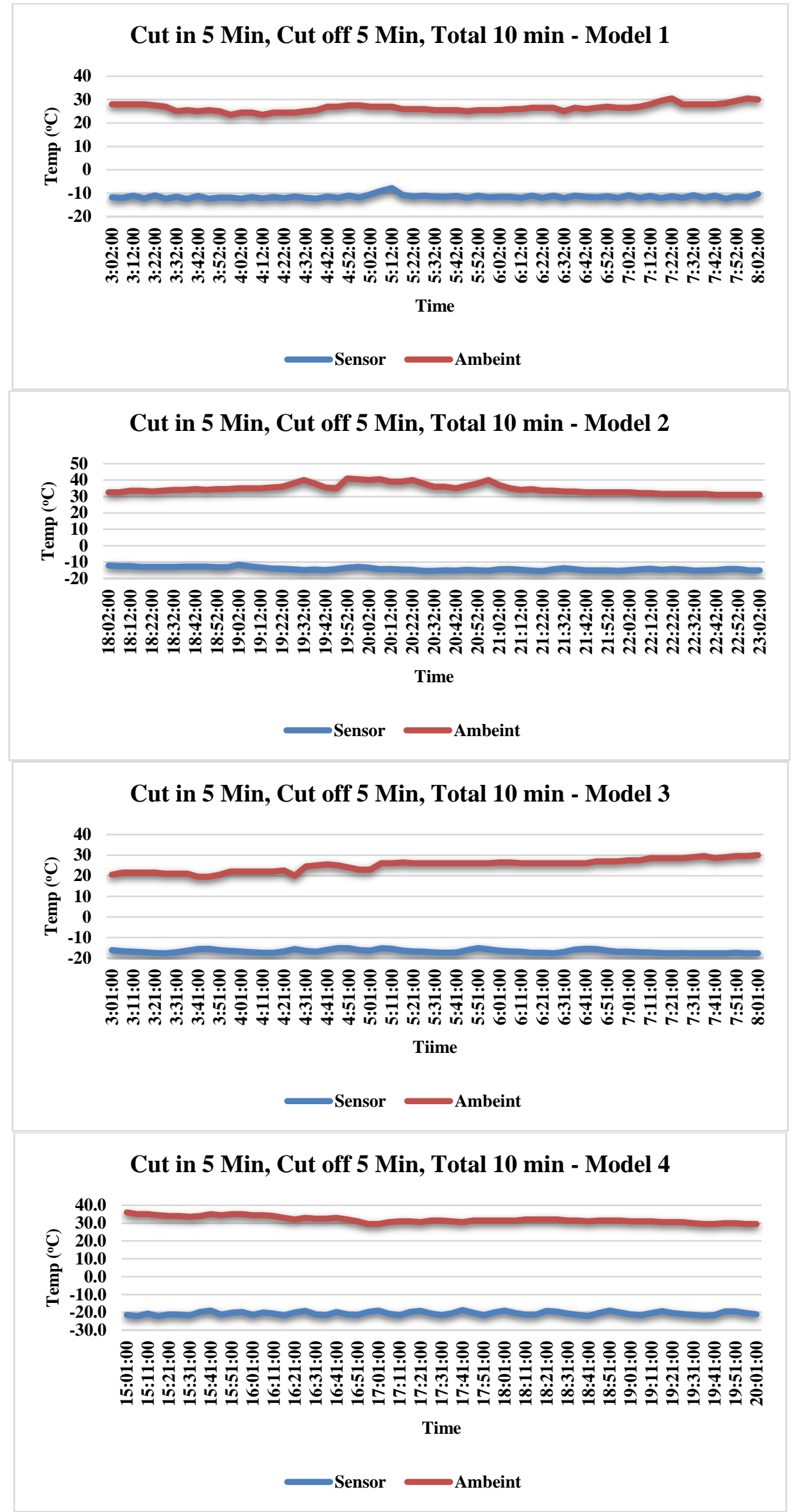

Fig. 8. The compressor cut in - cut off time before install VIPs 


\subsection{Model 2 - 4 Wheels large Truck}

As a result of the temperature results prior to installation of VIPs, as shown in Figure 7, it was found that the refrigerated cars were controlled an average of -14 degrees and defrosted 5 times a day due to the compressor operating at -25 degrees for evaporator temperature in low temperature condition. During the defrosting time, the temperature of the freezer room will rise to a maximum of -12 degrees due to the defrosting with heater. The average temperature along the route was 976 kilometers, averaging 34 degrees. The compressor takes 5 minutes to reach the set temperature, and it rises when the compressor stops running to the point where it starts up again in 5 minutes. The compressor cut in - cut off time before install VIPs, as shown in Figure 8.

As a result of the temperature results rear to installation of VIPs, as shown in Figure 9, it was found that the refrigerated cars were controlled an average of -14 degrees and defrosted 5 times a day due to the compressor operating at -25 degrees for evaporator temperature in low temperature condition. During the defrosting time, the temperature of the freezer room will rise to a maximum of -8 degrees due to the defrosting with heater. The average temperature along the route was 976 kilometers, averaging 33 degrees. The compressor takes 5 minutes to reach the set temperature, and it rises when the compressor stops running to the point where it starts up again in 10 minutes. The compressor cut in - cut off time after install VIPs, as shown in Figure 10.

Test results show that VIPs insulation can maintain the same temperature as without VIPS insulation but the time required for cut in cut off is better to install VIPs insulation. The energy saving effect comes from the moment when the compressor is stopped, which means saving fuel to be used in cooling as a result of VIPs insulation. When all the results are calculated as the energy saving result, it is obtained that over a distance of $976 \mathrm{~km}$, the fuel price is $25.79 \mathrm{baht} /$ liter. It was found that the fuel consumption rate before VIPs installation was $12.91 \mathrm{~km} /$ liter, and compared with the after VIPS installation at $13.32 \mathrm{~km} /$ liter, the fuel savings was $3.17 \%$.

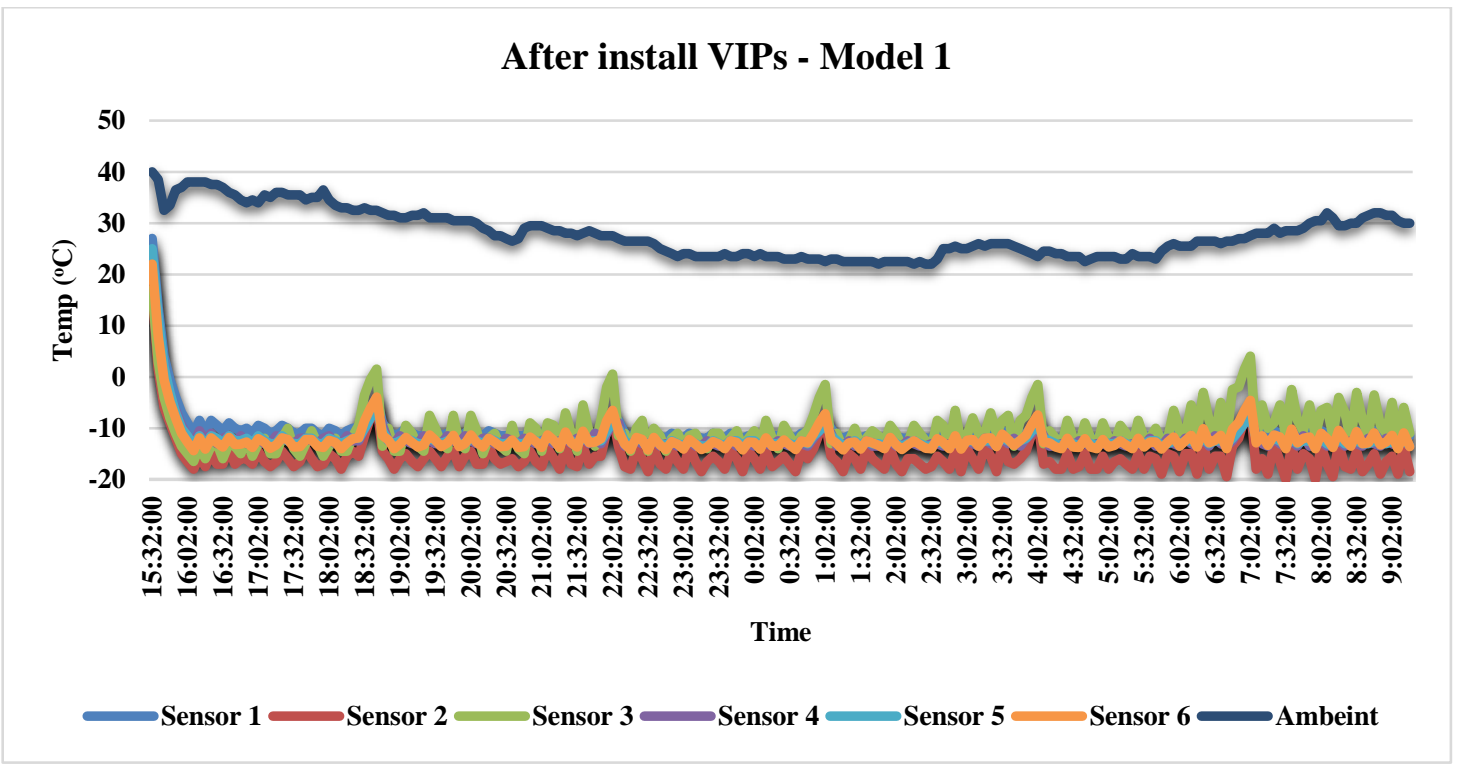




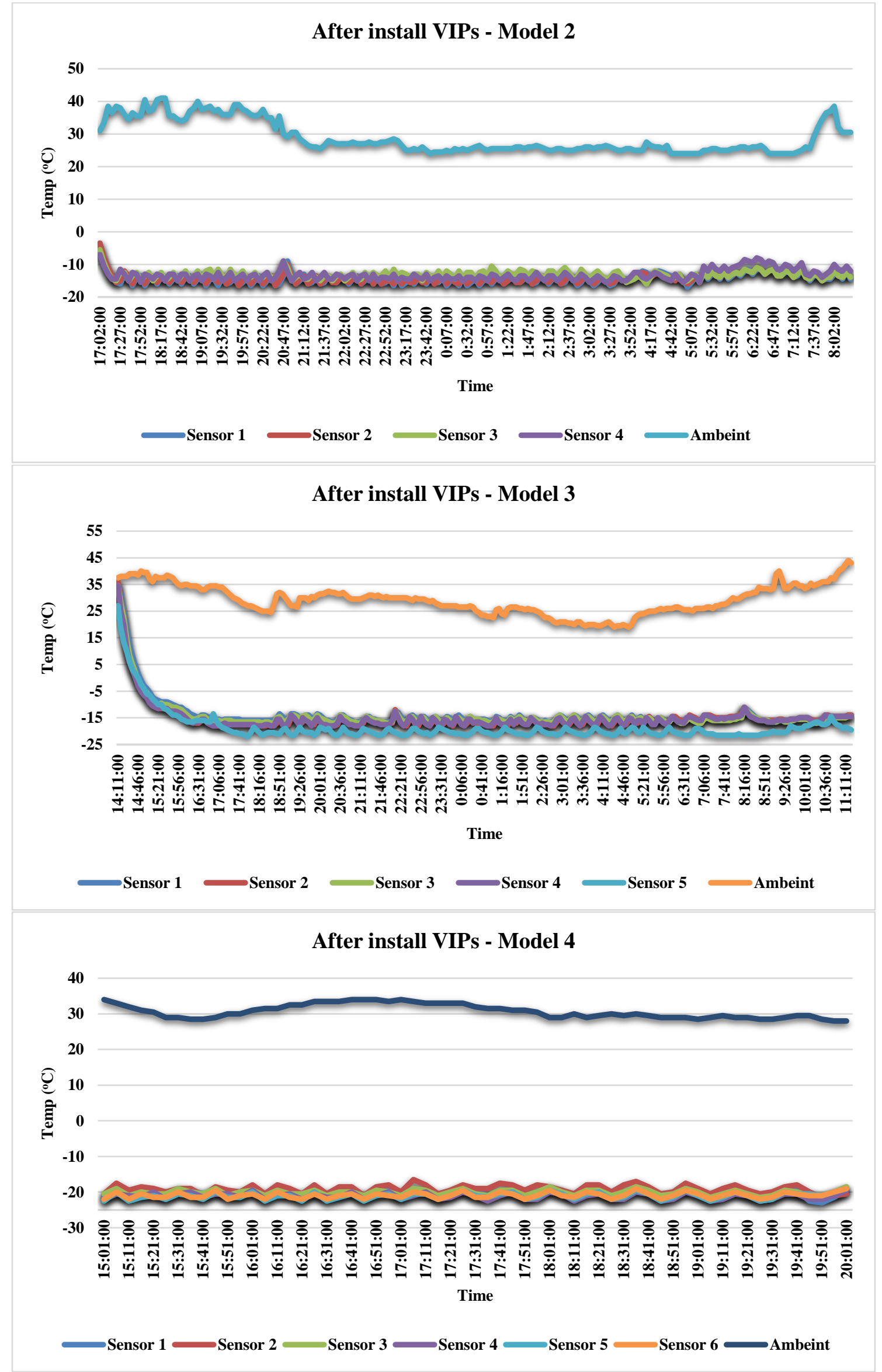

Fig. 9. Temperature results after install VIPs 


\subsection{Model 3 - 6 Wheels Truck}

As a result of the temperature results prior to installation of VIPS, as shown in Figure 7, it was found that the refrigerated cars were controlled an average of - 16 degrees and defrosted 22 times a day due to the compressor operating at -25 degrees for evaporator temperature in low temperature condition. During the defrosting time, the temperature of the freezer room will rise to a maximum of -15 degrees due to the defrosting with heater. The average temperature along the route was 1,025 kilometers, averaging 25 degrees. The compressor takes 5 minutes to reach the set temperature, and it rises when the compressor stops running to the point where it starts up again in 5 minutes. The compressor cut in - cut off time before install VIPs, as shown in Figure 8.

As a result of the temperature results rear to installation of VIPs, as shown in Figure 9, it was found that the refrigerated cars were controlled an average of -16 degrees and defrosted 27 times a day due to the compressor operating at -25 degrees for evaporator temperature in low temperature condition. During the defrosting time, the temperature of the freezer room will rise to a maximum of -15 degrees due to the defrosting with heater. The average temperature along the route was 1,025 kilometers, averaging 24 degrees. The compressor takes 10 minutes to reach the set temperature, and it rises when the compressor stops running to the point where it starts up again in 15 minutes. The compressor cut in - cut off time after install VIPs, as shown in Figure 10.

Test results show that VIPs insulation can maintain the same temperature as without VIPs insulation but the time required for cut in cut off is better to install VIPs insulation. The energy saving effect comes from the moment when the compressor is stopped, which means saving fuel to be used in cooling as a result of VIPs insulation. When all the results are calculated as the energy saving result, it is obtained that over a distance of $1,025 \mathrm{~km}$, the fuel price is $26.09 \mathrm{baht} /$ liter. It was found that the fuel consumption rate before VIPs installation was $4.88 \mathrm{~km} /$ liter, and compared with the after VIPs installation at $5.07 \mathrm{~km} /$ liter, the fuel savings was $3.98 \%$.

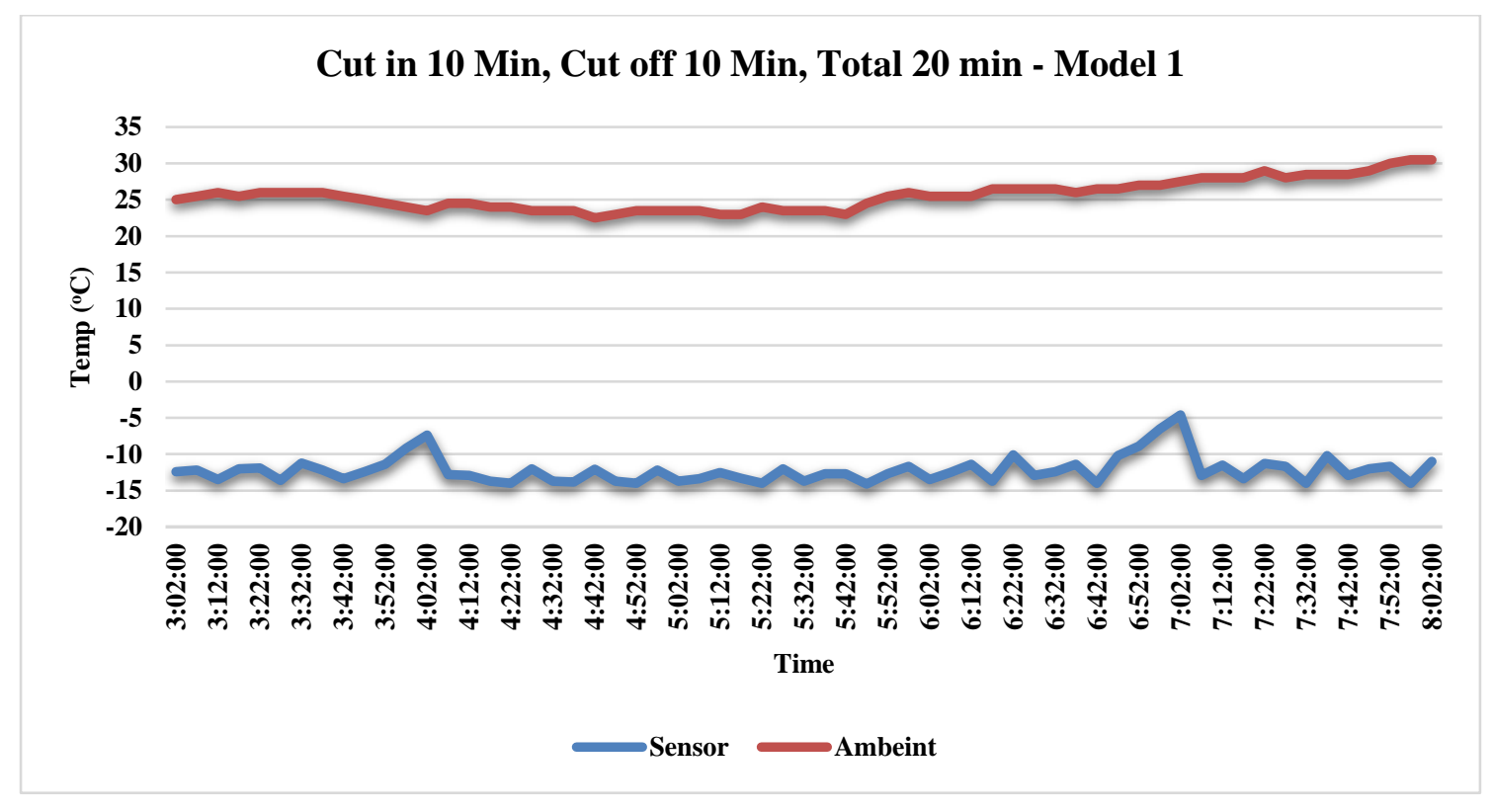




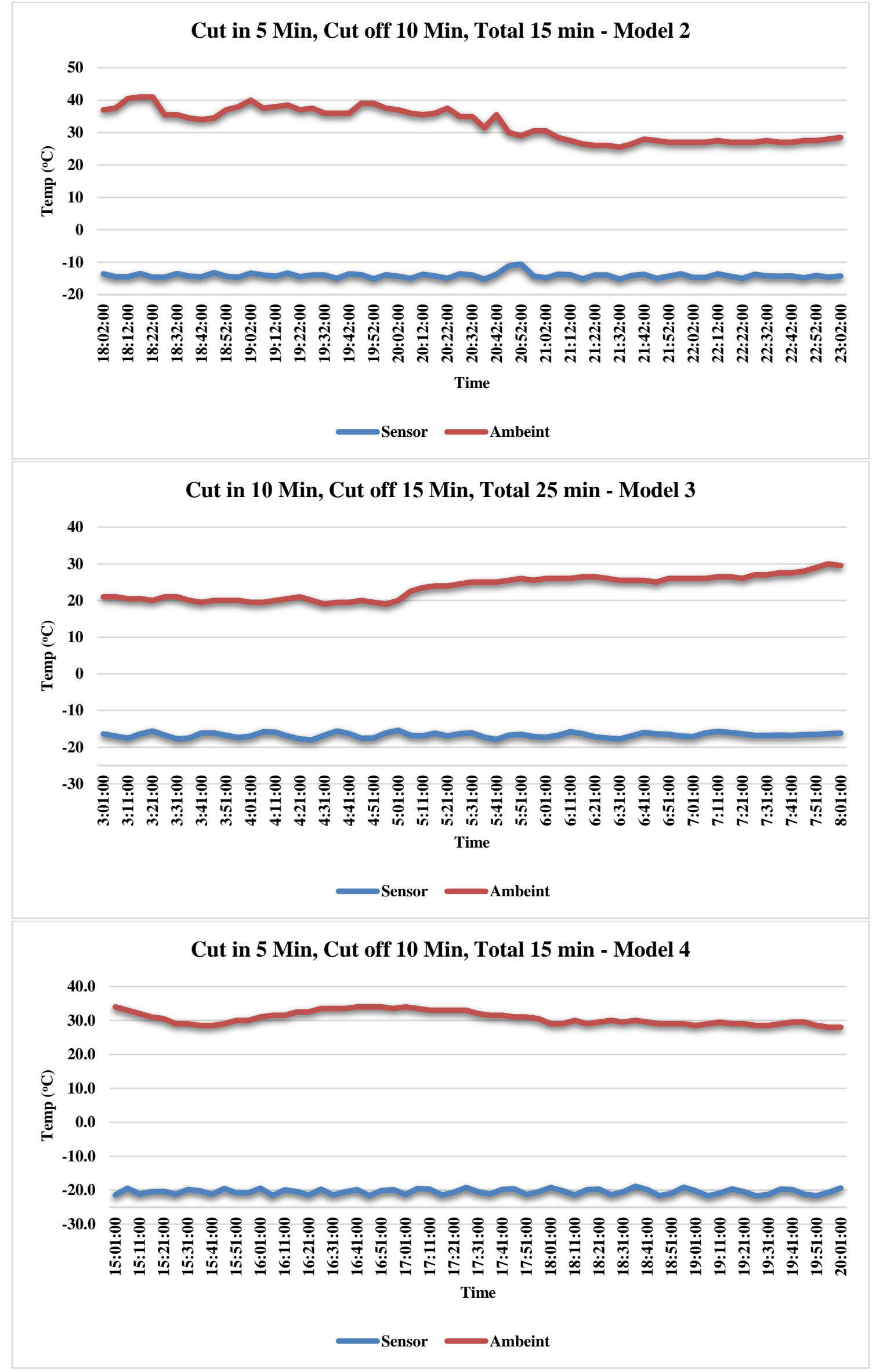

Fig. 10. The compressor cut in - cut off time after install VIPs 


\subsection{Model 4 - 10 Wheels Truck}

As a result of the temperature results prior to installation of VIPs, as shown in Figure 7, it was found that the refrigerated cars were controlled an average of -20 degrees and defrosted 15 times a day due to the compressor operating at -25 degrees for evaporator temperature in low temperature condition. During the defrosting time, the temperature of the freezer room will rise to a maximum of -18 degrees due to the defrosting with heater. The average temperature along the route was 1,036 kilometers, averaging 32 degrees. The compressor takes 5 minutes to reach the set temperature, and it rises when the compressor stops running to the point where it starts up again in 5 minutes. The compressor cut in - cut off time before install VIPs, as shown in Figure 8.

As a result of the temperature results rear to installation of VIPs, as shown in Figure 9, it was found that the refrigerated cars were controlled an average of -20 degrees and defrosted 18 times a day due to the compressor operating at -25 degrees for evaporator temperature in low temperature condition. During the defrosting time, the temperature of the freezer room will rise to a maximum of -18 degrees due to the defrosting with heater. The average temperature along the route was 1,036 kilometers, averaging 31 degrees. The compressor takes 10 minutes to reach the set temperature, and it rises when the compressor stops running to the point where it starts up again in 15 minutes. The compressor cut in - cut off time after install VIPs, as shown in Figure 10.

Test results show that VIPs insulation can maintain the same temperature as without VIPs insulation but the time required for cut in cut off is better to install VIPs insulation. The energy saving effect comes from the moment when the compressor is stopped, which means saving fuel to be used in cooling as a result of VIPs insulation. When all the results are calculated as the energy saving result, it is obtained that over a distance of $1,036 \mathrm{~km}$, the fuel price is $25.79 \mathrm{baht} /$ liter. It was found that the fuel consumption rate before VIPs installation was $2.40 \mathrm{~km} /$ liter, and compared with the after VIPs installation at $2.67 \mathrm{~km}$ / liter, the fuel savings was $11.33 \%$. The results of all 4 models, as shown in Table 2, it was found Model 1 (4 Wheels Truck) have best fuel savings followed by the Model 4 (10 Wheels Truck), Model 3 (6 Wheels Truck), and Model 2 (4 Wheels large Truck) respectively.

Table 2

Summary fuel savings

\begin{tabular}{|c|c|c|c|c|c|c|c|}
\hline \multirow[t]{2}{*}{ Model } & \multirow[t]{2}{*}{ Type } & \multicolumn{2}{|l|}{ Condition } & \multicolumn{3}{|c|}{ Compressor Operating Time (Min) } & \multirow{2}{*}{$\begin{array}{l}\text { fuel } \\
\text { consumption } \\
\text { rate } \\
\text { (km / liter) } \\
\end{array}$} \\
\hline & & & & Cut In & Cut Out & Total & \\
\hline \multirow[t]{4}{*}{1} & 4 & Chiller & With Out VIPs & 10 & 5 & 15 & 20.0 \\
\hline & Wheels & & With VIPs & 10 & 10 & 20 & 24.0 \\
\hline & Truck & Freezer & With Out VIPs & 5 & 5 & 10 & 7.1 \\
\hline & & & With VIPs & 10 & 10 & 20 & 8.3 \\
\hline \multirow[t]{4}{*}{2} & 4 & Chiller & With Out VIPs & 5 & 5 & 10 & 15.1 \\
\hline & Wheels & & With VIPs & 5 & 10 & 15 & 16.3 \\
\hline & large & Freezer & With Out VIPs & 5 & 5 & 10 & 13.0 \\
\hline & Truck & & With VIPS & 5 & 10 & 15 & 13.3 \\
\hline \multirow[t]{4}{*}{3} & 6 & Chiller & With Out VIPs & 5 & 5 & 10 & 5.3 \\
\hline & Wheels & & With VIPs & 5 & 10 & 15 & 5.5 \\
\hline & Truck & Freezer & With Out VIPs & 5 & 5 & 10 & 4.9 \\
\hline & & & With VIPs & 10 & 15 & 25 & 5.1 \\
\hline \multirow[t]{4}{*}{4} & 10 & Chiller & With Out VIPs & 5 & 5 & 10 & 2.3 \\
\hline & Wheels & & With VIPs & 5 & 10 & 15 & 2.4 \\
\hline & Truck & Freezer & With Out VIPs & 5 & 5 & 10 & 2.4 \\
\hline & & & With VIPs & 5 & 10 & 15 & 2.7 \\
\hline
\end{tabular}




\section{Conclusions}

In many countries, land transportation is still used as the primary transportation and cold storage trucks are used to distribute products to different locations. VIPs insulation is an alternative that can reduce the cooling energy consumption of oil-driven compressors. Demonstrates the potential to reduce energy consumption that can still be achieved in the future, people should research other types of cold storage trucks or research in the same way as the air wall by inserting VIPs insulation inside the external insulation to reduce heat transfer.

\section{Acknowledgement:}

This study was supported by the Prince of Songkla University and SANYO S.M.I. (Thailand) Co., Ltd.

\section{References}

[1] Chaitanoo, N., P. Ongkunaruk, and D. Leingpibul. "The use of physical simulation to evaluate thermal properties of food containers in cold chain logistics." In IOP Conference Series: Materials Science and Engineering, vol. 773, no. 1, p. 012018. IOP Publishing, 2020. https://doi.org/10.1088/1757-899X/773/1/012018

[2] Verma, Sankarshan, and Harjit Singh. "Vacuum insulation in cold chain equipment: A review." Energy Procedia 161 (2019): 232-241. https://doi.org/10.1016/j.egypro.2019.02.086

[3] Saengsikhiao, Piyanut, Juntakan Taweekun, Kittinan Maliwan, Somchai Sae-ung, and Thanansak Theppaya. "Investigation and Analysis of R463A as an Alternative Refrigerant to R404A with Lower Global Warming Potential." Energies 13, no. 6 (2020): 1514. https://doi.org/10.3390/en13061514

[4] Verma, Sankarshan, and Harjit Singh. "Vacuum insulation panels for refrigerators." International Journal of Refrigeration 112 (2020): 215-228. https://doi.org/10.1016/j.ijrefrig.2019.12.007

[5] Trancossi, Michele, Giuseppe Cannistraro, and Jose Pascoa. "Thermoelectric and solar heat pump use toward self sufficient buildings: The case of a container house." Thermal Science and Engineering Progress 18 (2020): 100509. https://doi.org/10.1016/i.tsep.2020.100509

[6] Mao, Shang, Ankang Kan, and Ning Wang. "Numerical analysis and experimental investigation on thermal bridge effect of vacuum insulation panel." Applied Thermal Engineering 169 (2020): 114980. https://doi.org/10.1016/j.applthermaleng.2020.114980

[7] Hashemi, Arman, Mahmood Alam, and Kenneth Ip. "Comparative performance analysis of Vacuum Insulation Panels in thermal window shutters." Energy Procedia $157 \quad$ (2019): $837-843$. https://doi.org/10.1016/j.egypro.2018.11.249

[8] Saengsikhiao, Piyanut, Juntakan Taweekun, Kittinan Maliwan, Somchai Sae-ung, and Thanansak Theppaya. "Development of Environmentally Friendly and Energy Efficient Refrigerants for Refrigeration Systems.". https://doi.org/10.32604/EE.2021.012860

[9] Mao, Shang, Ankang Kan, and Ning Wang. "Numerical analysis and experimental investigation on thermal bridge effect of vacuum insulation panel." Applied Thermal Engineering 169 (2020): 114980. https://doi.org/10.1016/i.applthermaleng.2020.114980

[10] Mao, Shang, Ankang Kan, Wenbing Zhu, and Yebaihe Yuan. "The impact of vacuum degree and barrier envelope on thermal property and service life of vacuum insulation panels." Energy and Buildings 209 (2020): 109699. https://doi.org/10.1016/i.enbuild.2019.109699

[11] Kunič, Roman. "Vacuum Insulation Panels (VIP)-An Assessment of the Impact of Accelerated Ageing on Service Life." Strojniški vestnik-Journal of Mechanical Engineering 58, no. 10 (2012): 598-606. https://doi.org/10.5545/svjme.2012.539

[12] Li, Xiangfeng, Changhai Peng, and Le Liu. "Experimental study of the thermal performance of a building wall with vacuum insulation panels and extruded polystyrene foams." Applied Thermal Engineering 180 (2020): 115801. https://doi.org/10.1016/j.applthermaleng.2020.115801

[13] Biswas, Kaushik, Tapan Patel, Som Shrestha, Douglas Smith, and Andre Desjarlais. "Whole building retrofit using vacuum insulation panels and energy performance analysis." Energy and Buildings 203 (2019): 109430. https://doi.org/10.1016/i.enbuild.2019.109430

[14] Saengsikhiao, Piyanut, Juntakan Taweekun, Kittinan Maliwan, Somchai Sae-ung Sae-ung, and Thanansak Theppaya. "The replacement of the R404A refrigeration system with the environmentally friendly R448A, to improve convenience store energy efficiency in Thailand." Journal of Advanced Research in Fluid Mechanics and Thermal Sciences 75, no. 1 (2020): 137-146. https://doi.org/10.37934/arfmts.75.1.137146 
[15] Saengsikhiao, Piyanut, Juntakan Taweekun, Kittinan Maliwan, Somchai Sae-ung, and Thanansak Theppaya. "The improvement of energy efficiency for refrigeration system in Thailand convenience store by digital scroll compressor." Journal of Advanced Research in Fluid Mechanics and Thermal Sciences 74, no. 1 (2020): 144-150. https://doi.org/10.37934/arfmts.74.1.144150

[16] Atsonios, loannis, loannis Mandilaras, and Maria Founti. "Thermal assessment of a novel drywall system insulated with VIPs." Energies 12, no. 12 (2019): 2373. https://doi.org/10.3390/en12122373

[17] Saengsikhiao, Piyanut, Juntakan Taweekun, Kittinan Maliwan, Somchai Sae-ung, and Thanansak Theppaya. "The Performance Simulation of The New R463A HFC/HFO/Carbon Dioxide Refrigerant with Lower GWP, As an Alternate Option for The R404A Refrigeration System." Journal of Advanced Research in Fluid Mechanics and Thermal Sciences 76, no. 1 (2020): 113-123. https://doi.org/10.37934/arfmts.76.1.113123 